\title{
Analisis Bibliometrik Menggunakan Vosviewer Terhadap Trend Riset Matematika Terapan Di Google Scholar
}

\author{
Arifin Karim $^{1, \text { a) }}$, Joko Soebagyo ${ }^{2, \text { b) }}$, Rahma Puspa Nuranti ${ }^{3, \text { c) }}$, Ana Luklu Uljanah ${ }^{4, \text { d) }}$ \\ ${ }^{1234}$ Universitas Muhammadiyah Prof. Dr. HAMKA \\ Email penulis: a) arifinkarim@uhamka.ac.id, b) jokosoebagyo@gmail.com, ${ }^{\text {c) }}$ rahmapuspa@uhamka.ac.id, d) \\ analukluuljanah@uhamka.ac.id
}

\begin{abstract}
Bibliometric analysis is the mapping of research research trends by processing metadata from Google Scolar. The aim is to find out research trends in applied mathematics. The research was conducted on April 30, 2021 through searching the Google Scholar database with the keywords applied mathematics with the publication name journal and the maximum number of results is 500 journals as a sample. Metadata retrieval using the Publish or Perish (POP) application version 7.31. The PoP data were then analyzed descriptively based on the publication year, publisher name, researcher productivity, and journal ranking. To get an accurate map of research developments, PoP data is exported to Exel CSV and Result as RIS file formats. CSV data was created in a pivot table and RIS data was analyzed using the VOSViewer (VV) application. The results of the research show that the number of publications of research results in the years 2005-2021 has fluctuated and is mostly published in Elsevier. The most prolific foreign researcher in publishing research results is Biher Bist with 14 articles. The VV visualization shows that the map of the development of applied mathematics research is divided into 5 clusters. Cluster 1 consists of 27 topics, cluster 2 consists of 15 topics, cluster 3 consists of 10 topics, cluster 4 consists of 7 topics, and cluster 5 consists of 3 topics with the most research covering mathematics, paper, problem, solution, system, university, department, science.
\end{abstract}

Keywords: Applied Mathematic, VOSViewer, Bibliometrik, Google Scholar, Publish or Perish

\begin{abstract}
Abstrak
Analisis bibliometerik adalah pemetaan trend riset penelitian dengan pengolahan metadata dari google scolar. Tujuannya untuk mengetahui trend riset tentang matematika terapan. Riset dilakukan pada bulan 30 April 2021 melalui penelusuran database google scholar dengan keywords applied mathematic dengan publication name journal dan maxsimum numbers of results adalah 500 jurnal sebagai sampel. Pengambilan metadata menggunakan aplikasi Publish or Perish (POP) versi 7.31. Data hasil PoP kemudian dianalisis secara deskriptif berdasarkan tahun terbit publikasi, nama publisher, produktivitas peneliti, dan ranking jurnal. Untuk mendapatkan peta perkembangan riset secara akurat, data PoP dieskpor ke format file Exel CSV dan Result as RIS. data CSV dibuat pivot table dan data RIS dianalisis menggunakan aplikasi VOSViewer (VV). Hasil riset menunjukkan bahwa jumlah publikasi hasil riset di tahun 2005-2021 mengalami peningkatan secara fluktuatif dan terbanyak dipublikasikan dalam Elsevier. Peneliti asing yang paling produktif mempublikasikan hasil penelitian adalah Biher Bist sebanyak 14 artikel. Melalui visualisasi VV menunjukkan bahwa peta perkembangan riset matematika terapan terbagi menjadi 5 kluster. Kluster 1 terdiri dari 27 topik, kluster 2 terdiri 15 topik, kluster 3 terdiri 10 topik, kluster 4 terdiri 7 topik, dan kluster 5 terdiri 3 topik dengan penelitian terbanyak mencakup mathematics, paper, problem, solution, system, university, department, science.
\end{abstract}

Kata kunci: Matematika Terapan, VOSViewer, Bibliometrik, Google Scholar, Publish or Perish

Copyright (c) 2021 Karim, Soebagyo, Nuranti, Uljanah

$\triangle$ Corresponding author:

Email Address: arifinkarim@uhamka.ac.id

Received 3 Agustus 2021, Accepted 3 Agustus 2021, Published 20 Agustus 2021

https://doi.org/10.21009/jrpmj.v3i2.22264 


\section{PENDAHULUAN}

Pendidikan merupakan investasi berharga di era industri 4.0. Melalui pendidikan, cita-cita membangun sumber daya manusia Indonesia bermutu agar mampu mampu bersaing di era industri 4.0 akan terwujud. Undang-undang Sisdiknas No. 20 Tahun 2003 pasal 1 ayat 1, menyatakan bahwa pendidikan adalah usaha sadar dan terencana untuk mewujudkan suasana belajar dan proses pembelajaran agar siswa secara aktif mengembangkan potensi dirinya untuk memiliki kekuatan spiritual kegamaan, pengendalian diri, kepribadian, kecerdasan, ahlak mulia, serta keterampilan.

Pemerintah melalui Menteri Pendidikan dan Kebudayaan Nasional telah menetapkan berbagai kebijakan untuk mengembangkan potensi peserta didik di era globalisasi diantaranya adalah penetapan mata pelajaran matematika sebagai mata pelajaran wajib di jenjang pendidikan dasar dan menengah. Penguasaan matematika di jenjang pendidikan dasar dan menengah adalah modal dasar penerapan matematika di perguruan tinggi. Azizah et al., (2018) mengatakan bahwa matematika perlu diberikan kepada siswa sejak sekolah dasar sebagai prasyarat untuk mengembangkan ilmu pengetahuan dan teknologi.

Banyak mahasiswa mengalami kesulitan dalam mata kuliah matematika terapan di perguruan tinggi. Saputra \& Purwanti (2010) mengatakan bahwa matakuliah ini meliputi materi Sistem Bilangan, Bilangan Kompleks, Determinan dan matriks, Fungsi dan limit, Diferensial, serta integral. Sebagai ilmu dasar (Basic Science), mata kuliah Matematika Terapan I akan menunjang mata kuliah yang lain, utamanya pada bidang ilmu eksakta dan teknik, maka seharusnya setiap mahasiswa "harus sangat menguasai" mata kuliah matematika agar mampu menguasai mata kuliah yang lain. Akan tetapi pada kenyataannya hampir sebagian besar mahasiswa selalu beranggapan bahwa mata kuliah matematika sulit dipahami, membosankan dan identik dengan soal-soal yang sulit dipecahkan. Hal ini dapat diindikasikan dari hasil prestasi belajar mahasiswa dalam kurun 5 (lima) tahun terakhir yang selalu hasilnya di bawah standar yang diinginkan.

Hal ini menggambarkan bahwa matematika terapan sangat berguna namun masih banyak yang mengalami kesulitan. Matematika telah diaplikasi dalam berbagai bidang kehidupan modern seperti statistika, tehnik mesin, tehnik informaika dan lain-lain. Dalam bidang statistika misalnya matematika digunakan dalam perhitungan cepat pemilu dan pertumbuhan penduduk. Lebih lanjut Soebagyo (2017) mengatakan bahwa salah satu disiplin ilmu yang paling kental menggunakan dan menerapkan matematika adalah bidang teknik. Sebagai contoh, dalam bidang teknik industri dan teknik mesin, persamaan diferensial digunakan untuk menghitung besar gaya peredam, integral untuk menghitung luas dan volume benda yang tidak beraturan. Bidang teknik informatika menggunakan matematika diskrit untuk mengolah data digital dalam sistem operasi komputer dan masih banyak disiplin ilmu lain yang menggunakan matematika dalam pekerjaannya.

Penerapan ilmu matematika dalam berbagai bidang kehidupan modern, diperlukan ketrampilan tingkat tinggi yang harus ditanamkan sejak pendidikan dasar. Sumartini \& Matematis (2016) 
mengatakan bahwa berkenaan dengan pentingnya kemampuan pemecahan masalah, National Council of Teacher of Mathematics (NCTM, 2000) mengatakan bahwa dalam pelaksanaan pembelajaran matematika di sekolah, guru harus memperhatikan lima kemampuan matematika yaitu: koneksi (conections), penalaran (reasoning), komunikasi (communications), pemecahan masalah (problem solving), dan representasi (representations). Berdasarkan NCTM dapat dilihat bahwa salah satu yang menjadi fokus utama tujuan pembelajaran matematika adalah kemampuan pemecahan masalah.

Kemampuan pemecahan masalah sangat berguna bagi peserta didik karena sebagai modal dasar dalam mengaplikasikan matematika dalam dunia nyata. Penerapan matematika dalam kehidupan modern menjadi modal berharga sebuah bangsa. Banyaknya penerapan matematika dalam bidang kehidupan, menunjukkan bahwa sumber daya manusia di sebuah negara tersebut bermutu dan akan melahirkan banyak inovasi-inovasi yang mempermudah kehidupan manusia. Atas dasar itu, perlu dilakukan pemetaan perkembangan hasil penelitian tentang matematika terapan yang telah dilakukan oleh para peneliti. Konstribusi dari penelitian ini adalah ingin menemukan penelitian tentang matematika terapan yang masih jarang diteliti dan untuk pengembangan matematika terapan di masa mendatang.

\section{KAJIAN TEORI}

\subsection{Database Google Scholar}

Google scholar diluncurkan pada tahun 2004 oleh induk perusahaan Google. Google scolar menyedikan database publikasi ilmiah dengan fitur berupa layanan pencarian jurnal-jurnal bereputasi secara online baik secara nasional dan internasional. Rafika et al., (2017) mengatakan bahwa tahun 2004 Google meluncurkan layanan terbaru yaitu Google Scholar atau juga bisa disebut Google Cendekia dalam bahasa indonesia. Google Scholar ini menyediakan layanan seperti informasi yang pastinya bermanfaat berupa PDF (Portable Document Format) secara lengkap dan gratis.Pada umumnya Google Scholar digunakan oleh kalangan pelajar dan mahasiswa untuk mencari referensi dalam membuat karya ilmiahnya.

Database Google Scholar menawarkan kemudahan mencari literatur akademis secara luas dan bebas. Peneliti dapat menemukan seluruh bidang ilmu dan referensi ilmiah dari satu tempat secara gratis. Database dalam google scolar meliputi makalah peer-reviewed, thesis, buku, abstrak, dan artikel dari penerbit akademis, komunitas profesional, pusat data pracetak, universitas, dan organisasi akademis lainnya. Google Scolar akan bekerja dengan cara mengidentifikasi penelitian paling relevan dari seluruh penelitian akademis. Hasil paling relevan akan selalu muncul pada halaman pertama.

Google Scholar memiliki peralatan canggih untuk melacak, menganalisis, dan memvisualisasikan hasil penelitian dengan sangat cepat dalam nol koma detik. Google Scholar mampu 
memetakan hasil-hasil penelitian berdasarkan tahun peneltian, author, keywords, publisher, tahun terbit, keywords, yang dapat disetting di dashboar sebelah kiri.

\subsection{Publish or Perish}

Publish or perish atau PoP merupakan sebuah software yang dapat digunakan untuk mengambil metadata karya ilmiah semua bidang ilmu secara gratis. PoP menyediakan layanan akses metadata secara gratis di CrossRef, Google Scholar, Google Scholar Profiles, Microsoft Academic*, PubMed, Scopus* dan WoS. Asy'ari et al., (2021) mengatakan bahwa Harzing's publish or perish merupakan perangkat lunak sebagai alat bantu yang dapat dipergunakan secara gratis yang mempermudah dalam proses pencari artikel dengan tersusun rapih dan terkoneksi dalam berbagai situs publikasi (hingga saat ini metadata yang di jangkau dalam harzing's publish or perish yaitu Google Scholar, Microsoft Academic, Scopus, dan Web of Science) sehingga memberikan kemudahan peneliti dalam pencari artikel yang menjadi bahan rujukan dalam studi literatur. Selanjutnya data yang terkumpul dianalisis menggunakan metode tinjauan pustaka melalui teknik traditional review.

Dalam analisis ini peneliti mengambil data dari google scolar menggunakan Pop karena Pop menyedikan fitur canggih filter kategori jenis metadata yang dimaskud yaitu publication name tipe jurnal. Pop juga menyediakan fitur Keywords dan title word yang memungkan peneliti dapat menemukan metadata jurnal yang akurat.

\subsection{VOSViewer}

VOSViewer atau disebut juga VV adalah sebuah software yang digunakan untuk memvisualkan peta bibliometrik atau data set yang berisi field bibliografi seperti judul, pengarang, penulis, jurnal, dan lain-lain. Dalam penelitian, VV digunakan untuk analisis bibliometrik, memetakan topik untuk penelitian terbaru, mencari referensi yang paling banyak digunakan pada bidang tertentu dan lainnya. Jan \& Ludo (2010) mengatakan bahwa VOSviewer can for example be used to construct maps of authors or journals based on cocitation data or to construct maps of keywords based on cooccurrence data. The program offers a viewer that allows bibliometric maps to be examined in full detail. VOSviewer can display a map in various different ways, each emphasizing a different aspect of the map. It has functionality for zooming, scrolling, and searching, which facilitates the detailed examination of a map. The viewing capabilities of VOSviewer are especially useful for maps containing at least a moderately large number of items (e.g., at least 100 items).

VV mampu membaca dataset dari berbagai situs jurnal online seperti Google Scholar, Web of Science, Scopus, Dimension, dan Pubmed. Format dataset RIS, Endnote, dan RefWork juga bisa dibaca 
oleh VV. Melalui fitur API, VV dapat membaca/mengambil data dari Crossreff, Pubmed PMC, Semantic Scholar, OCC, COCI, Wikidata.

\section{METODE}

Metode yang digunakan dalam riset ini adalah bibliometrik melalui pemetaan metadata jurnal ilmiah bidang matematika terapan yang didapatkan dari situs Google Scholar. Alasannya karena kajian bibliometrik merupakan salah satu kajian riset informasi dalam bidang ilmu perpustakaan yang mudah dan hemat biaya.

Kajian topik ini dilakukan pada literatur dengan menerapkan metode matematika dan statistika. Hakim (2020) mengatakan pengertian bibliometrik adalah kajian yang mengukur perkembangan penelitian, literatur, buku atau dokumen pada bidang tertentu baik secara kuantitatif atau kualitatif dengan menggunakan metode statistika. Bibliometrik dibagi menjadi dua kelompok besar yaitu bibliometrik deskriptif dan bibliometrik perilaku. Bibliometrik deskriptif menggambarkan karakteristik suatu literatur sedangkan bilbliometrik perilaku mengkaji hubungan yang terbentuk antara komponen literatur tersebut (Royani, Tupan, \& Kusumaningrum, 2019).

Lebih lanjut dikatakan oleh Tupan (2016) bahwa Nicolai (2010) menjelaskan bahwa aplikasi bibliometrik dapat dibagi menjadi dua bagian, yaitu: 1) perhitungan bibliometrik (kinerja) indikator pada tingkat perilaku yang berbeda; dan 2) analisis serta visualisasi jaringan bibliometrik. Analisis menggunakan indicator bibliometrik di-bedakan menjadi deskriptif bibliometric dan bibliometrik evaluatif (Van Leeuwen dalam Nicolai, 2010). Bibliometrik deskriptif mengambil pendekatan topdown, mencoba untuk mendapatkan gambaran besar, seperti output penelitian suatu negara dalam berbagai bidang, proporsi berbagai bidang dan perubahan dari waktu ke waktu. Sementara itu, bibliometrik evaluative adalah alat untuk menilai kinerja penelitian unit yang lebih kecil seperti kelompok penelitian atau individu dengan menggunakan pendekatan bottom-up, yaitu mengumpulkan semua publikasi yang relevan dari unit masing-masing.

Peniliti menggunakan database Google Scolar dengan aplikasi PoP karena pada fitur PoP dapat memfilter kategori jurnal yang dimaksud selain itu aplikasi tersebut free pay. Pengumpulan data dilakukan pada bulan 30 April 2021 dengan Publication Name jurnal dan keywords Applied Mathematic dalam kurun waktu 2005-2021 seperti terlihat pada Gambar 1.

Berdasarkan hasil penelusuran diperoleh publikasi dalam bentuk artikel sebanyak 500 judul artikel. Data berupa jumlah publikasi pertahun memuat artikel tentang matematika terapan, penulis, asal penulis, produktifitas, publisher yang dianalisis menggunakan Microsoft Excel 2016. Sedangkan untuk peta perkembangan publikasi internasional bidang matematika terapan dianalisis dengan menggunakan aplikasi VOSViewer karena aplikasi Ini dapat membuat kluster riset dan free pay. 


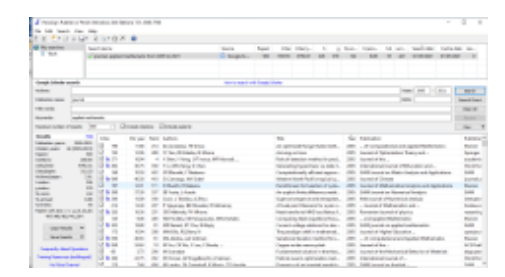

Gambar 1. Hasil penelusuran metadata melalui PoP Versi 7.31

\section{HASIL DAN PEMBAHASAN}

\subsection{Jumlah Penelitian}

Berdasarkan hasil penelusuran pada database Google Scholar menunjukkan bahwa perkembangan riset matematika terapan selama kurun waktu 2005-2021 mengalami kondisi fluktuatif. Perkembangan riset bidang matematika terapan meningkat secara signifikan mulai tahun 2006-2008 seperti terlihat pada Tabel 1. Setelah itu terjadi pasang-surut jumlah publikasi ilmiah tentang matematika terapan. Untuk tahun 2020 mengalami penurunan sangat drastis.

Tabel 1. Jumlah publikasi perkembangan penelitian bidang matematika terapan berdasarkan tahun

\begin{tabular}{|c|c|}
\hline Tahun Publikasi & Jumlah \\
\hline 2005 & 54 \\
\hline 2006 & 38 \\
\hline 2007 & 68 \\
\hline 2008 & 54 \\
\hline 2009 & 49 \\
\hline 2010 & 44 \\
\hline 2011 & 27 \\
\hline 2012 & 31 \\
\hline 2013 & 36 \\
\hline 2014 & 27 \\
\hline 2015 & 13 \\
\hline 2016 & 9 \\
\hline 2017 & 37 \\
\hline 2018 & 4 \\
\hline 2019 & 4 \\
\hline 2020 & 2 \\
\hline 2021 & 1 \\
\hline Jumlah & 498 \\
\hline
\end{tabular}

Menariknya tahun 2012 dan 2013 mengalami kenaikan lagi disebabkan surat edaran Direktur Jenderal Pendidikan Tinggi No. 152 tahun 2012, bahwa setiap sarjana, Magister dan Doktor untuk dapat lulus harus mempublikasikan tugas akhirnya di Jurnal nasional, nasional terakreditasi dan Internasional. Selain itu ada aturan tentang kenaikan jenjang kepangkatan beberapa jabatan fungsional 
mempersyaratkan publikasi hasil riset dan pemikiran dalam jurnal ilmiah bertaraf internasional. Setelah itu 2013 penelitian tentang matematika terapan mengalami pasang surut.

\subsection{Jurnal inti dalam Publikasi Internasional Bidang Matematika Terapan}

Berdasarkan 500 artikel riset yang diperoleh dari hasil penelusuran melalui database Google Schoolar diseleksi menjadi dalam 498 judul jurnal. Dari 498 jurnal, peringkat 10 besar jurnal inti dalam publikasi bidang matematika terapan di Google Schoolar adalah Elvesier, Siam, Wiley Online Library.

Tabel 2 menunjukkan bahwa peringkat 10 besar jurnal yang mempublikasikan hasil riset bidang Matematika terapan adalah Elvesier sebanyak 112 artikel, disusul Siam sebanyak 34 artikel, Wiley Online Library 32 artikel, Springer dan acadpubl.eu masing-masing 30 artikel, World Scientific 26 artikel, journals.sagepub.com dan degruyter.com masing- masing 19 artikel dan seterusnya.

Tabel 2. Sepuluh besar Publisher Jurnal IImiah matematika terapan

\begin{tabular}{|l|l|l|}
\hline No & \multicolumn{1}{|c|}{ Nama Publikasi } & Jumlah \\
\hline 1 & Elvesier & 112 \\
\hline 2 & Siam & 34 \\
\hline 3 & Wiley Online Library & 32 \\
\hline 4 & Springer dan acadpubl.eu & 30 \\
\hline 5 & World Scientific & 26 \\
\hline 6 & journals.sagepub.com dan degruyter.com & 19 \\
\hline 7 & hindawi.com & 16 \\
\hline 8 & Taylor \& Francis dan arc.aiaa.org & 15 \\
\hline 9 & researchgate.net & 12 \\
\hline 10 & ACS Publications & 11 \\
\hline
\end{tabular}

\subsection{Peneliti Yang paling Produktif}

Pemetaan perkembangan riset matematika terapan menggunakan VOSViewer 1.6.16. Dalam pemilihan type of data, peneliti menggunakan cretae a map based on bibliographic data. Lalu dalam data source menggunakan read data from reference manager files dengan supported file types RIS. Kemudian pada counting method menggunakan full counting dengan Maximum number of authors per document sebanyak 20 dan Minimum number of document of an author sebanyak 4. Hasilnya, dari 1059 peneliti, ada 10 yang memenuhi kriteria 


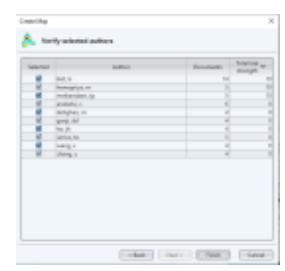

Gambar 1. Peneliti paling produktif dalam matematika terapan

Terdapat sepuluh peneliti yang paling banyak mempublikasikan riset tentang matematika terapan. Peneliti paling banyak mempublikasikan hasil risetnya adalah Biher Bist, Asisten Profesor Department of Mechanical Engineering di Barath University, India yaitu sebanyak 14 artikel. Diurutan kedua adalah M.Hemapriya, Asisten Profesor Department of Civil Engineering di Barath University, India. Kemudian urutan ketiga adalah TP Meikandan, Asisten Profesor Department of Civil Engineering di Barath University, India. Ketiga peneliti tersebut sering mempublikasikan hasil penelitian bersama. Korelasi ketiganya terlihat dalam gambar 2

Gambar 2. Korelasi Peneliti paling produktif dalam matematika terapan

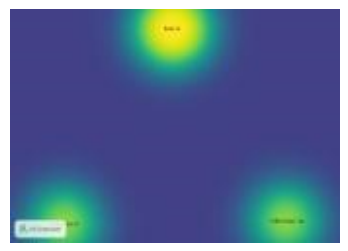

Gambar 3. Korelasi Peneliti paling produktif dalam matematika terapan dalam mode density

\subsection{Peta Perkembangan Riset Matematika Terapan}

Pemetaan perkembangan riset matematika terapan menggunakan VOSViewer 1.6.16. dalam pemilihan type of data, peneliti menggunakan create a map based text data. Lalu dalam data source menggunakan read data from reference manager files dengan supported file types RIS. Kemudian pada counting method menggunakan Binary counting dengan miniumum numbers of occurences of term sebanyak 8 dan number of term to be selected sebanyak 63 . 


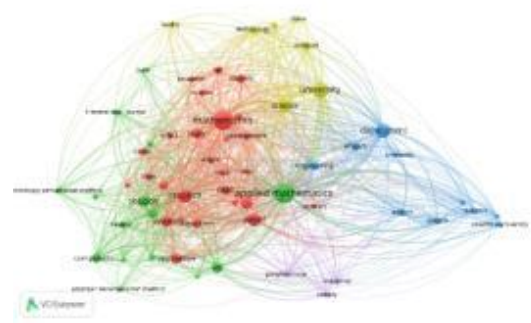

Gambar 4. Hasil pemetaan matematika dengan mode tampilan Network Visualization

Terdapat 62 item yang terbagi dalam 5 kluster. Kluster 1 sebanyak 27 item terdiri dari abstract, alghoritm, analysis, application, approach, area, article, development, education, effect, field, mathematics, number, numerical solution, order, page, paper, parameter, problem, research, set, student, study, system, time, work dan year. Adapun kluster 2 sebanyak 15 item terdiri dari adomian decomposition, applied mathematics, comparison, computation, computational, homotopy perturbation method, internasional jurnal, journal, math, mechanics, pure, review, solution, variational iteration method dan vol. Kluster 3 sebanyak 10 item terdiri dari applied physics, author, chemistry, Columbia university, department, engineering, new york, physics, search, usa. Kluster 4 sebanyak 7 item terdiri dari china, faculty, institute, school, science, technology dan university. Sedangkan kluster 5 sebanya 3 item terdiri dari google scholar, industrial dan society.

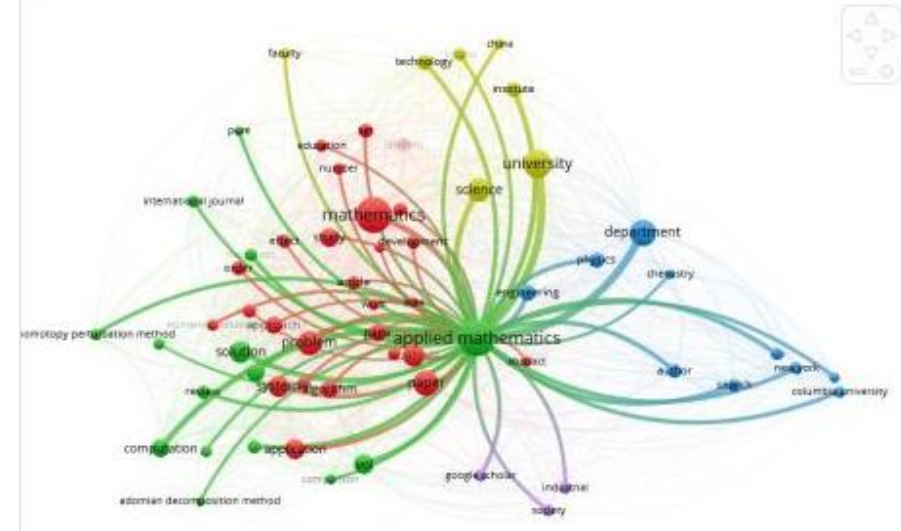

Gambar 5. Hasil pemetaan matematika dengan mode tampilan Network Visualization

Applied mathematic atau matematika terapan terhubung ke 60 link penelitian dalam 5 kluster. Beberapa link paling kuat dengan applied mathematic adalah mathematics, university, science, department. Sedangkan link yang berhubungan tidak begitu kuat adalah comparison, adomian decomposition method, abstract, numerical solution dan sebagainya. Link yang berhubungan tidak begitu kuat tersebar di 5 cluster ditandai dengan bulatan kecil. Bulatan-bulatan kecil tersebut masih belum banyak hasil risetnya dan berpeluang untuk dilakukan riset terbarukan. 


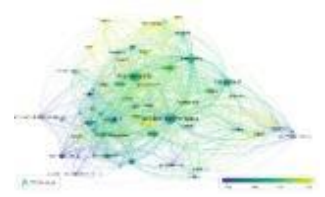

Gambar 6. Hasil pemetaan matematika dengan mode tampilan Overlay Visualization

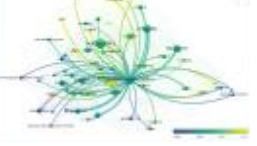

Gambar 7. Hasil pemetaan matematika dengan mode tampilan Overlay Visualization

Riset terbaru yang paling erat dengan matematika terapan adalah pada tahun 2011. Riset tersebut berkaitan dengan usa, search, review, analysis, algoritm, development, effect, china, technology, number dan pure

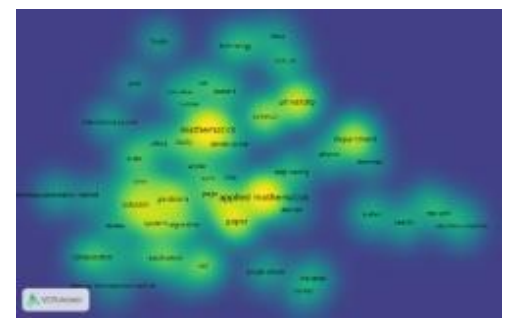

Gambar 8. Hasil pemetaan matematika dengan mode tampilan Density Visualization

Mode tampilan density di atas memperlihatkan bahwa penelitian paling banyak terkait dengan matematika terapan adalah mathematics, paper, problem, solution, system, university, department, science ditandai dengan warna kuning menyala. Semakin terang warnanya maka semakin banyak risetnya. Adapun riset yang masih sangat sedikit adalah adomian decomposition, homotopy perturbation method, google scolar, industrial, engineering dan lain-lain ditandai dengan warna yang tidak menyala. Dengan demikian, maka terbuka peluang untuk riset terbarukan dengan mengambil item-item tersebut.

\section{KESIMPULAN}

Bagian ini menjelaskan kesimpulan umum dari hasil penelitian sesuai dengan tujuan penelitian. Berdasarkan penelitian yang telah dilakukan, maka dapat diperoleh kesimpulan Berdasarkan hasil penelitian di atas dapat disimpulkan bahwa jumlah penelitian tentang matematika terapan mengalami fluktuatif. Publikasi terbanyak terjadi pada tahun 2007 sebanyak 68 artikel. Peneliti yang paling banyak mempublikasikan hasil risetnya adalah Biher Bist, Asisten Profesor Department of Mechanical Engineering di yaitu sebanyak 14 artikel. Diurutan kedua dan ketiga adalah M.Hemapriya dan TP Meikandan yang sama-sama berasal dari Barath University, India. penelitian paling banyak terkait 
dengan matematika terapan adalah mathematics, paper, problem, solution, system, university, department, science ditandai dengan warna kuning menyala. Semakin terang warnanya maka semakin banyak risetnya. Adapun riset yang masih sangat sedikit adalah adomian decomposition, homotopy perturbation method, google scolar, industrial, engineering dan lain-lain ditandai dengan warna yang tidak menyala. Dengan demikian, maka terbuka peluang untuk riset terbarukan dengan mengambil item-item tersebut.

Berdasarkan kesimpulan di atas, maka peneltian terbaru selanjunya yang menjadi perhatian para peneliti matematika terapan adalah berkaitan dengan adomian decomposition, homotopy perturbation method, google scolar, industrial dan engineering. Karena riset tentang ini masih sangat sedikit

\section{DAFTAR PUSTAKA}

Asy'ari, R., Dienaputra, R. D., Nugraha, A., Tahir, R., Rakhman, C. U., \& Putra, R. R. (2021). Kajian Konsep Ekowisata Berbasis Masyarakat Dalam Menunjang Pengembangan Pariwisata: Sebuah Studi Literatur. Pariwisata Budaya: Jurnal Ilmiah Pariwisata Agama Dan Budaya, 6(1), 9-19.

Azizah, M., Sulianto, J., \& Cintang, N. (2018). Analisis Keterampilan Berpikir Kritis Siswa Sekolah Dasar pada Pembelajaran Matematika Kurikulum 2013. Jurnal Penelitian Pendidikan, 35(1), 6170. https://doi.org/10.15294/jpp.v35i1.13529

Hakim, L. (2020). Analisis Bibliometrik Penelitian Inkubator Bisnis Pada Publikasi Ilmiah Terindeks Scopus. Jurnal Ilmiah Manajemen E-ISSN, 8(2), 176-189.

Jan, N., \& Ludo, V. E. (2010). Software survey: VOSviewer, a computer program for bibliometric mapping. 523-538. https://doi.org/10.1007/s11192-009-0146-3

Rafika, A. S., Yunan Putri, H., \& Widiarti, F. D. (2017). Sebagai Sumber Baru Untuk Kutipan. Cerita, 3(2), 13. https://core.ac.uk/download/pdf/285996222.pdf

Saputra, H., \& Purwanti, D. (2010). Peningkatan Kualitas Pembelajaran Matematika Terapan I Pada Mahasiswa Program Diploma Iii Teknik Elektro Unnes Dengan Metode Pemberian Tugas Melalui E-Learning. 27.

Soebagyo, J. (2017). Profil Pembelajaran Dalam Mengakomodasi Mathematical Proficiency. Euclid, 3(2), 474-490. https://doi.org/10.33603/e.v3i2.328

Sumartini, T. S., \& Matematis, K. P. (2016). Peningkatan Kemampuan Pemecahan Masalah Matematis Siswa melalui Pembelajaran Berbasis Masalah. 5.

Tupan. (2016). Perkembangan Hasil Penelitian Bidang Pertanian Di Indonesia. Visi Pustaka, 18(3), 217-230.

How to cite : Karim, A., Soebagyo, J., Nuranti, R. P., \& Uljanah, A. L., 2021. Analisis Bibliometrik Menggunakan Vosviewer Terhadap Trend Riset Matematika Terapan Di Google Scholar. Jurnal Riset Pendidikan Matematika Jakarta. 3(2). 23-33. https://doi.org/10.21009/jrpmj.v3i2.22264

To link to this article: https://doi.org/10.21009/jrpmj.v3i2.22264 